\title{
Partial uterine perforation and ovarian embedment of misplaced intrauterine device: a case report
}

\author{
Abhishek Kaushik*, Dalpat S. Rajpurohit, Kirti Chaturvedy, Sunil Vishnoi, \\ Anish H. Panduranga, Asaf Ali K. Kammar, Girija Nandvanshi
}

Department of Radiodiagnosis, Dr. S. N. Medical College, Jodhpur, Rajasthan, India

Received: 14 May 2020

Accepted: 05 June 2020

\section{*Correspondence:}

Dr. Abhishek Kaushik,

E-mail: abhi94spmc@gmail.com

Copyright: ( $)$ the author(s), publisher and licensee Medip Academy. This is an open-access article distributed under the terms of the Creative Commons Attribution Non-Commercial License, which permits unrestricted non-commercial use, distribution, and reproduction in any medium, provided the original work is properly cited.

\begin{abstract}
Intrauterine devices (IUDs) are the commonest form of contraceptive method in use globally. IUDs like other methods of contraception may be associated with its own complications. The major risk includes uterine perforation with embedment, migration, and/or expulsion. A 35 year old female who had a history of postpartum IUD insertion 10 years ago was referred to our institute with complains of severe lower abdominal pain and vomiting since 10 days. Transabdominal and transvaginal ultrasound (TAS/TVS) were done. Ultrasound led to the final diagnosis of ovarian embedment of the IUD. Laparotomy with IUD removal was successfully performed. This case report highlights one of the rare complications of IUD migrating to the left ovary in a patient presenting with lower abdominal pain. In a patient with history an IUD insertion in situ, lower abdominal pain and missing threads on examination should wary the gynaecologist to the possibility of total or partial transmigration of the device into the pelvis or abdomen.
\end{abstract}

Keywords: Misplaced IUD, Ultrasound, Ovary, Abdominal pain, Laparotomy

\section{INTRODUCTION}

The IUDs are forms of long-acting reversible contraception (LARC) which provide the most effective reversible contraceptive options to women. ${ }^{1}$ There are different types, hormonal and non-hormonal. The most popularly used type of nonhormonal IUD in India and other developing nation is the copper $(\mathrm{Cu}) \mathrm{T} 380 \mathrm{~A}$ and $\mathrm{T}$ $200 .^{2}$ The most important impediment associated with IUD insertion is uterine perforation. Eighty-five percent of perforations do not affect adjacent viscera; however, in $15 \%$ of cases it can lead to complications in the adjacent organs. IUDs could migrate to the bladder, sigmoid colon, and other adjacent organs, but not much have been reported on migration and embedment to the ovary. ${ }^{3-5}$ The location of an in-situ IUD can be assessed with ultrasonography (USG) (TAS/TVS). Currently the accepted treatment is laparotomy with IUD removal. This case report is aimed at introducing another rare case of partial uterine perforation with embedment in left ovary with patient complaining of lower abdominal pain and vomiting.

\section{CASE REPORT}

Patient aged 35 years was referred to the obstetrics and gynaecology department of our institute with chief complaints of lower abdominal pain since 10 days and vomiting since 4 days.

Past history revealed that an IUD was inserted 10 years back at the time of her delivery. Mode of delivery was vaginal delivery, and was conducted at a community health centre (CHC) at Jaisalmer, Rajasthan, India. As IUD was inserted at CHC possibility of IUD insertion by a relatively less skilled person was apparent.

On clinical examination there was mild tenderness in the pelvic region and no strings of the IUD were seen. 
A pelvic radiograph was done that confirmed the presence of an in-situ IUD. Pelvic radiograph revealed that an IUD was noted in-situ in the pelvis below the pelvic brim, it was located slightly deviated towards left side from midline (Figure 1).

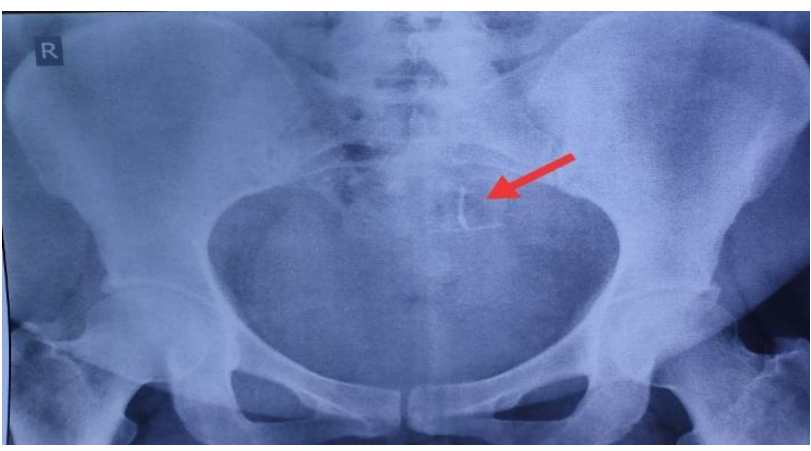

Figure 1: Pelvic radiograph reveals that an IUD was noted in-situ in the pelvis below the pelvic brim, it was located slightly deviated towards left side from midline.

Next TAS/TVS ultrasound was done using prosound ALOKA alpha 6 USG medical systems with 2-5 MHz curvilinear probe and $5 \mathrm{~Hz}$ endovaginal curved linear TVS probe.

It revealed that vertical stem was seen in the endometrial cavity, however left part of the horizontal arm was seen causing penetration of the uterus (was passing through endometrium, myometrium and serosa) in the fundus region, and was seen extending to the left ovary. Left ovary was in close proximity to the fundus (Figure 2 and 3 ).

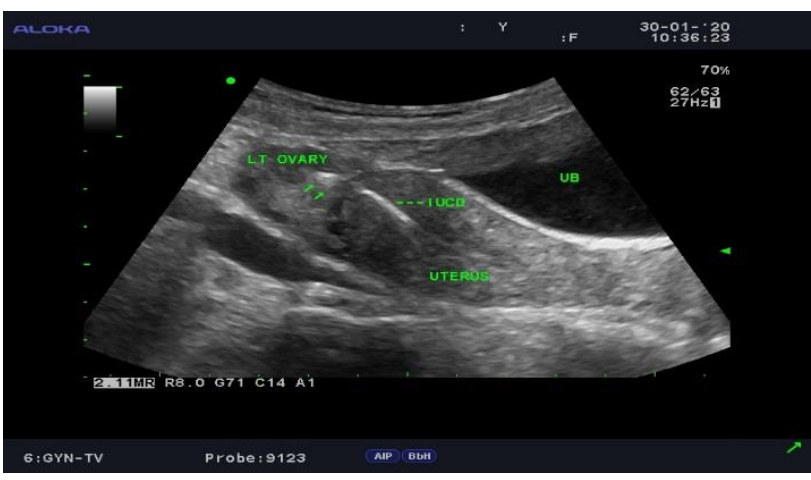

Figure 2: USG image, shows that vertical stem of the IUD was seen in the endometrial cavity, however left part of the horizontal arm was seen causing

penetration of the uterus (was passing through endometrium, myometrium and serosa) in the fundus region.

Rest of the abdomen USG study was normal with no evidence of free fluid in peritoneal/pelvic cavity.

Hence the final impression of transmigrated IUD with partial uterine perforation (type D2 as per Zakin et al classification) and embedment of the horizontal arm in the left ovary was made. ${ }^{6}$

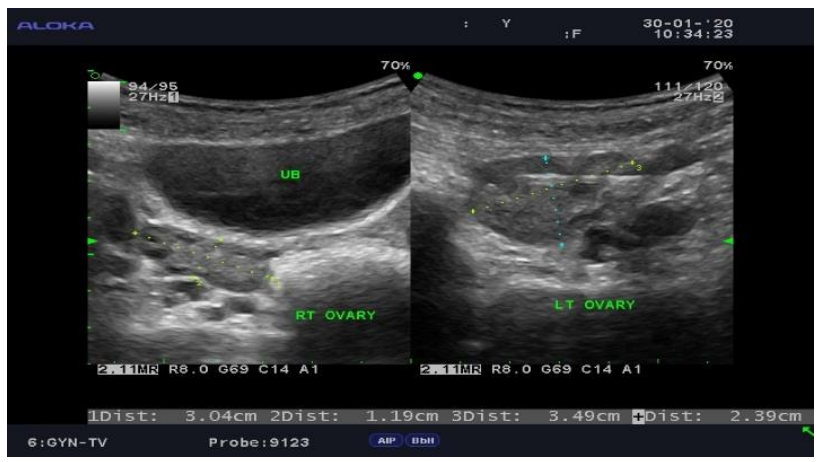

Figure 3: Normal right ovary and horizontal arm of the IUD is seen penetrating the left ovary (UB: urinary bladder).

The patient underwent laparotomy with IUD removal that confirmed the findings of USG. At the time of operation left ovary was seen to be adherent to the fundus and there was no evidence of hemoperitoneum, bowel perforation. The patient did well post operatively and was discharged on the 4th day post operatively (Figure 4 and 5).

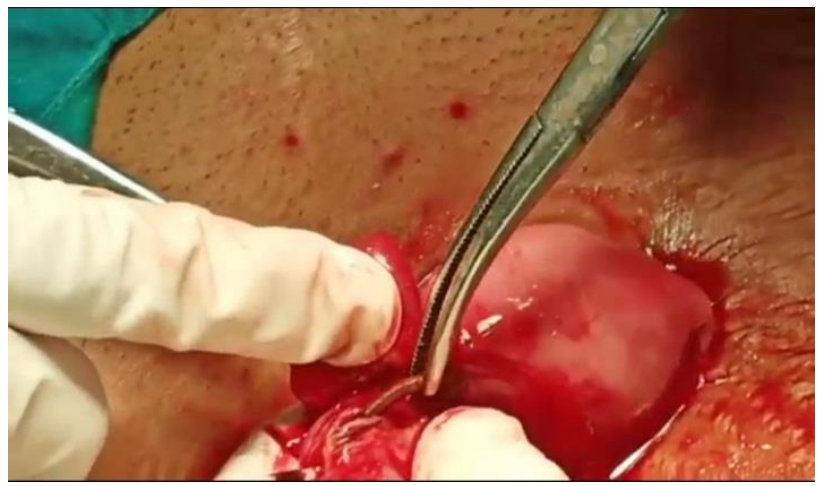

Figure 4: The findings of the USG were confirmed intraoperatively, seen in the image is the IUD penetrating the left ovary.

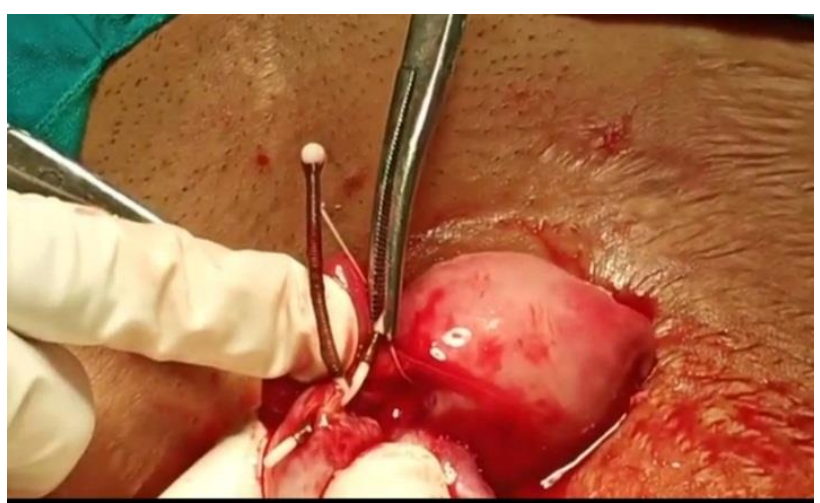

Figure 5: Intraoperative images shows the partial perforation of IUD, patient underwent laparotomy with IUD removal. 


\section{DISCUSSION}

More than 130 million women around the world use IUD, making IUDs the most common contraceptive method in the world. ${ }^{7}$ Copper ions released from $\mathrm{Cu}$-IUDs accentuate the inflammatory response and reach levels in the luminal fluids of the genital tract that are harmful for spermatozoa and embryos. ${ }^{8}$ They are offered to women in whom combined hormonal contraception is contraindicated, and in women desirous of long-term reversible contraception. ${ }^{9}$

The most serious complication associated with IUD insertion is uterine perforation. The incidence has been estimated to range from 0 to 13 perforations per 1,000 insertions. ${ }^{6,10-15}$ The incidence of IUD perforation is directly related to the device, skill of the operator, as well as the size and configuration of the uterus-anteverted versus retroverted, and underlying uterine anomalies uterus and the time span between pueperium and insertion. ${ }^{10,11,15}$ Risk during the puerperium is estimated at 2.5 per 1,000 insertions. ${ }^{16}$

Patients with an underlying uterine perforation may be completely asymptomatic or can present with varying symptoms that include pelvic pain, dyspareunia, abnormal vaginal bleeding, inability to palpate IUD strings, and a positive pregnancy test. ${ }^{17}$ In cases of suspected perforation first step is per speculum examination to look for IUD strings. Visualization of the IUD strings exiting the cervical os does not rule out partial or complete uterine perforation, this point must always be kept in mind by clinician. Pelvic radiograph can be performed to determine whether IUD is in pelvis or has been expelled out. Next USG (TAS/TVS) can be performed to localize the IUD, and to look for any uterine perforation if any. USG can also delineate the relation of the device with adjacent organs such as small bowel, UB and ovary.

Uterine perforation can be partial or complete (as per the classification system proposed by Zakin et al), complete perforation is diagnosed when the device has passed through all uterine layers - endometrium, myometrium, and serosa to lie freely in the peritoneal cavity (most commonly at the pouch of Douglas) or enveloped by omentum or traveling into other rarer locations. ${ }^{6}$ Further partial perforation can be classified as A1 major part of the device is in endometrial cavity, A2 (when device is mainly located in the myometrium), in the type B IUD lies completely in the myometrium, in the type $\mathrm{C}$ perforation the device has extension into the peritoneal cavity but is still fixed in the myometrium. In a type $\mathrm{D}$ perforation, parts of the IUD are situated in all three compartments and further divided into D1 and D2 depending on complexity of its removal laproscopically.

Verma et al reviewed the literature regarding uterine perforation with IUDs from medline/ovid and found very few reported cases of IUD embedded in the ovary, because of inability of IUD to penetrate the thick ovarian capsule, the IUDs are generally located adjacent to the ovary. ${ }^{5}$ The site of the perforated IUD can be confirmed with TAS/TVS, hysteroscopy, abdominal x-ray or computed tomography (CT) scan. ${ }^{18-21}$ The acceptable treatment of uterine perforation is surgical removal of the IUD either by laparoscopy or exploratory laparotomy because of the risk of intra-abdominal adhesion formation and possible damage to adherent organs..$^{6,22,23}$

We describe a case report where the patient had a history of $\mathrm{Cu}$ T 380 A insertion 10 year back at a community health centre (possibility of being inserted by a less experienced professional was there) and presented with history of lower abdominal pain, vomiting since 10 days. The threads were not visible at per speculum examination and she was referred at our department for pelvic radiograph and TAS/TVS to localize the IUD. On TAS it revealed IUD has perforated uterus and was its horizontal arm was lying embedded in the left ovary.

The likelihood of uterine perforation with all its complications for health and liability should always be considered in any case of unexplained abdominal pain, uterine bleeding or missing strings on follow-up vaginal exam. In the work-up process prior to localizing the device, pregnancy should be ruled out first, TVS is considered to be the preferred tool for locating a lost IUD. Lower abdominal pain in a patient with a history of IUD insertion should alert the clinician to the possibility of total or partial transmigration of the device into the pelvis or abdomen.

\section{CONCLUSION}

While being an uncommon phenomenon, uterine perforation with an IUD is an important complication that must be explained to patients, prevented if possible by taking all steps to insert devices safely, and diagnosed and managed appropriately. High index of suspicion and alertness regarding the possibility of IUD transmigration in view of history of insertion by less experienced professionals, no visualization of threads at cervical os examination can lead to early diagnosis and timely management.

\section{ACKNOWLEDGEMENTS}

The authors would like to thank the department of obstetrics and gynaecology, S. N. Medical College, Jodhpur for providing us intraoperative images of the procedure (laparotomy followed by IUD removal).

\section{Funding: No funding sources \\ Conflict of interest: None declared \\ Ethical approval: Not required}

\section{REFERENCES}

1. American College of Obstetricians and Gynecologists. ACOG Practice Bulletin No. 121: Long-acting reversible contraception: Implants and 
intrauterine devices. Obstet Gynecol. 2011;118:18496.

2. Mustafa M. Erosion of an intrauterine contraceptive device through the bladder wall causing calculus: Management and review of the literature. Urol Int. 2009;82:370-1.

3. Özdemir H, Mahmutyaz CO, Lu K, Tanr Verdi H. Migration of an intrauterine contraceptive device to the ovary. J Clin Ultrasound. 2004;32(2):91-4.

4. Rovati M, Raveglia F, Baisi A, De Simone M, Cioffi U. Ovarian transmigration of intrauterine device. J Obstet Gynaecol Res. 2016;42:1889-90.

5. Verma U, Verma N. Ovarian embedding of a transmigrated intrauterine device: A case report and literature review. Arch Gynecol Obstet. 2009;280:275-8.

6. Zakin D, Stern WZ, Rosenblatt R. Complete and partial perforation and embedding following insertion of intrauterine devices. I. Classification, complications, mechanism, incidence, and missing string. Obstet Gynecol Surv. 1981;36:335-53.

7. Tatum HJ. Intrauterine contraception. Am J Obstet Gynecol. 1972;112:1000-23.

8. Ortiz ME, Croxatto HB, Bardin CW. Mechanisms of action of intrauterine devices. Obstet Gynecol Surv. 1996;51(12):42-51.

9. Gemzell-Danielsson K, Berger C, Lalitkumar PGL. Emergency contraception - Mechanisms of action. Contraception. 2013;87:300-8.

10. Rosen E. Intrauterine contraceptive devices: a method of localization. Am J Obstet Gynecol. 1965;93:896-7.

11. Millen A, Austin F, Berenstein G. Analysis of 100 cases of missing IUD strings. Contraception. 1978;18:485-95.

12. Valle RF, Sciarra JJ, Freeman DW. Hysteroscopic removal of intrauterine devices with missing Wlaments. Obstet Gynecol. 1977;49:55-60.

13. Schoenfeld A, Pardo J, Engelstein D, Ovadia J, Servadio C. Bladder perforation by an intrauterine device. J Clin Ultrasound. 1991;19:175-7.
14. Carson SA, Gatlin A, Mazur M. Appendiceal perforation by Copper-7 intrauterine contraceptive device. Am J Obstet Gynecol. 1981;141:586-7.

15. Heartwell SF, Schlesselman S. Risk of uterine perforation among users of intrauterine devices. Obstet Gynecol. 1983;61:31-6.

16. Intrauterine Contraceptive Devices-a new look. WHO Population Reports, Geneva. World Health Organization, 1989.

17. Mederos R, Humaran L, Minervini D. Surgical removal of an intrauterine device perforating the sigmoid colon: a case report. Int J Surg. 2008;6:60-2.

18. Andersson K, Ryde-Blomqvist E, Lindell K, Odlind V, Milsom I. Perforations with intrauterine devices. Report from a Swedish survey. Contraception. 1998;57:251-5.

19. Adoni A, Ben Chenrit A. The management of intrauterine devices following uterine perforation. Contraception. 1990;43:77-81.

20. Levsky JM, Herkovits M. Incidental detection of a transmigrated intrauterine device. Emerg Radiol. 2005;11(5):312-4.

21. Bartalena T, Pascali E, Rinaldi MF, Marasco R, Bassi F, Alboni C, Gavelli G. Transmigrated intrauterine device discovered 17 years after its insertion. Australas Radiol. 2007;51:284-6.

22. Pirvany IR, Boddy K. Colonic Wstula caused by a previously inserted intrauterine device. A case report. Contraception. 1997;56:337-9.

23. Serryan RFM. Endoscopic removal of intrauterine contraceptive devices. In: van der Pas HFM, Dieben TOM (eds) State of the art of the IUD, 1st edn. Kluwer, London. 1989;173-217.

Cite this article as: Kaushik A, Rajpurohit DS, Chaturvedy K, Vishnoi S, Panduranga AH, Kammar AAK, et al. Partial uterine perforation and ovarian embedment of misplaced intrauterine device: a case report. Int J Reprod Contracept Obstet Gynecol 2020;9:5114-7. 